$$
\begin{gathered}
\text { WORKING PAPERS } \\
\text { No. 17/2012 (83) } \\
\text { ALEKSANDRA KOLASA } \\
\text { LIFE CYCLE INCOME } \\
\text { AND CONSUMPTION PATTERNS } \\
\text { IN TRANSITION }
\end{gathered}
$$




\title{
Life Cycle Income and Consumption Patterns in Transition
}

\author{
Aleksandra Kolasa \\ Faculty of Economic Sciences \\ University of Warsaw \\ National Bank of Poland \\ e-mail: aleksandra.kolasa@nbp.pl
}

\begin{abstract}
There is vast literature examining how households' income and consumption change over the life cycle. These studies, however, are usually restricted to developed economies. The main objective of this paper is to add to this literature by investigating the life cycle profiles and relative income mobility in a transition economy, facing rapid structural economic and social changes, such as Poland. I show that, in contrast to the US, where income inequality over the life cycle follows a roughly linear trend, the age-variance profile of income in Poland is hump-shaped. This finding might indicate that the income process at a micro level in Poland exhibits less persistence than in the US. The estimates of relative income mobility confirm this conjecture.
\end{abstract}

\section{Keywords:}

consumption, income, life cycle profiles, income inequality, relative income mobility, transition economy

JEL:

D12, D31, D91, E21, C14, D63

\footnotetext{
Disclaimer:

The views expressed in this paper are my own and not necessarily those of the National Bank of Poland or the University of Warsaw. This paper benefited from comments by Micha1 Gradzewicz, Ryszard Kokoszczyński, Marcin Kolasa and Michał Rubaszek. All remaining errors are mine.
} 


\section{Introduction}

There is vast literature examining how households' income and consumption change over the life cycle. These studies, however, are usually restricted to developed economies, such as the United States (US), Japan or the United Kingdom (UK). It is ex ante not clear if the results obtained for this relatively stable group can be generalized to other economies, including ex-communist Central and Eastern European countries. In particular, it is reasonable to expect that rapid structural economic and social changes experienced by households in transition economies might make their individual income and consumption processes deviate from those reported in the US and old EU member states, leading to differences observed at a more aggregate level.

The general objective of this paper is to add to the literature by investigating the life cycle profiles and relative income mobility in a transition economy, such as Poland. There are two more specific objectives of this article. The first one is to study the evolution of households' distribution of income and consumption over the life cycle in Poland, focusing on two first moments, i.e. the mean and variance. The life cycle profiles are analyzed separately for more and less educated households, which allows to determine how the consumption-savings choices are affected by the level of education. The second objective is to analyze the mobility of Polish households between income quintiles using the transition matrices. The ultimate aim is to compare the obtained results with similar studies for developed countries and thus identify the crucial specific factors driving income mobility in Poland, and in transition economies more generally. A useful byproduct of the results obtained in this paper is a set of characteristics, mainly life cycle profiles, which can be used to estimate macroeconomic models, in particular general equilibrium models with households experiencing uninsurable income shocks (see Cagetti, 2003; Gourinchas and Parker, 2002).

While constructing the life cycle profiles of income and consumption, I follow the approach first adopted for this type of analysis by Fernández-Villaverde and Krueger (2007). More specifically, a dependent variable is estimated using a seminonparametric partially linear model, in which cohort and year effects are controlled for by dummy variables, while the age-dependence is modeled using a nonparametric method. This approach allows to obtain smoothed estimates while imposing relatively few restrictions on the data.

In general, the findings on the mean of the logarithm of income and consumption distribution are broadly in line with the literature for developed economies. More specifically, income and consumption profiles exhibit a significant hump over the life cycle, even after accounting for changes in family size. However, in contrast to the US, where consumption over the life cycle grows at a relatively stable rate up to the age of 50, in Poland a sharp increase is observed below the age of 30 and then average consumption growth becomes moderate. Interestingly, a significantly higher growth rate in the 25-30 phase of life occurs only for the relatively educated individuals.

There is a number of studies investigating inequalities in income and consumption over the life cycle. In their influential paper, Deaton and Paxson (1994) presented both empirical and theoretical evidence of an increasing trend of inequality in income and consumption over the life cycle up to the retirement age. As further investigated by Storesletten et al. (2004), the life cycle profile of earnings inequality in the US grows at a relatively stable rate and thus can be approximated by a linear trend. A different pattern is observed in Japan, where according to Abe and Yamada (2009) there is a strong age dependence of income risk, which makes the age-variance income profile highly non-linear.

According to my results, yet another effect can be observed in Poland. The inequality of income over the life cycle is hump-shaped. After a rise in the early phase of household life, it remains quite 
stable for household head aged between 30 and 55. This finding might indicate that the income process in Poland exhibits less persistence than that in the US. Interestingly, there exists heterogeneity in inequality profiles between households with and without an academic degree. While the inequality pattern for all individuals is dominated by the shape of the less educated households, income inequality between households with a university degree exhibits a growing, roughly linear trend over the life cycle, similar to that in the US. However, this conclusion is somewhat weakened by wide confidence intervals associated with the age-variance profile for educated households.

This life cycle analysis is complemented by an investigation of the relative income mobility in Poland at the micro level. Income mobility has been the topic of a number of studies devoted to particular countries. The estimates for the US can be found i.a. in Auten and Gee (2007); Díaz-Giménez et al. (2011). The relative income mobility in the People's Republic of China was studied by Khor and Pencavel (2006) and Khor and Pencavel (2010). The former article compares the mobility indices in urban China with those in the US and OECD countries, the latter evaluates changes in income mobility over time and between urban and rural households. As regards crosscountry comparisons, Aaberge et al. (2002) claim that although there exist significant differences in terms of income inequality, the pattern of income mobility in the Scandinavian countries and the US is remarkably similar. Fabig (1998) emphasizes that the estimates of income mobility depend on the measure of income imposed, which is especially evident when countries differ in terms of the tax and transfer system. He shows that income mobility in West Germany is higher than in the US and the UK when calculated on a basis of gross income and lower when net income is used instead. Overall, evidence on the relative income mobility differences between the developed countries is not conclusive. However, in general, immobility measures are roughly similar between developed economies and significantly higher than those reported for the developing and transition countries, where the greater level of mobility is observed (see i.a. Khor and Pencavel, 2006).

To my knowledge, the evidence on income mobility in Central and Eastern European formerly communist countries is scarce (though some estimates for the Russian Federation are presented in Lukiyanova and Oshchepkov, 2011). To fill this gap, I calculate the estimates for Poland and then compare them with those for other countries (mainly the US). I show that Polish households are relatively more mobile between income quintiles than the American ones and only a small part of this difference can be explained by different shapes of the income distribution. In general, relative income mobility in Poland is more similar to that observed in other developing or transition economies (such as China or Russia) than to that obtained for developed countries.

The rest of this paper is organized as follows. In Section 2 I present the estimates of average income and consumption over the life cycle as well as the age-profile of income and consumption inequality. Section 3 is devoted to relative income mobility. Section 4 concludes. Technical description and comparison of the datasets used are presented in the Data appendix.

\section{Life cycle income and consumption profiles in Poland in 2000-2010}

The aim of this section is to present the life cycle patterns of income and consumption in Poland. I start with a description of the data used in this study, then move on to the estimation technique. The section ends up with a discussion of the results, where the last part is devoted to the sensitivity analysis. 


\subsection{Data}

This study is based on cross sectional data from the Polish Households Budget Survey (HBS) covering the period 2000-2010. The HBS is the largest and most accurate Polish household level survey on income and consumption. It is conducted every year by the Polish Central Statistical Office on a sample of around 37 thousand of Polish households. It collects households' monthly income and spending data, as well as a number of other socio-economic characteristics (see the Data appendix for the more precise description of the data).

To construct the income and consumption profiles, I use individual households' total monthly available net income and total monthly expenditures on consumer goods and services, adjusted for inflation with the consumer price index. To control for family size, an OECD square root equivalence scale is applied, i.e. income and consumption are divided by the square root of the number of household members. I assume that a household head has an academic degree if he or she declares higher or post-secondary education.

\subsection{Estimation method}

To construct the life cycle profiles of the first two moments of the logarithm of households' income or consumption distribution, I follow the approach first adopted for this type of analysis by FernándezVillaverde and Krueger (2007) and also used i.a. by Yang (2009). In the first step, a pseudo-panel (or a synthetic cohort panel, see Deaton, 1985) is created such that households are grouped in cohorts by the age of household heads observed in a particular year (or equivalently the household head's date of birth). Then, for each cohort and each period of time, the mean and the variance of the logarithm of income and consumption are calculated. In order to maintain a reasonable number of observations for each year-cohort unit, the sample is restricted to household heads aged between $18-85 .^{1}$ This gives $(85-17) *(2010-1999)=748$ records, each containing on average 500 individuals $^{2}$. The calculated moments are weighted by population shares provided in the HBS.

To estimate the life cycle profiles, I specify the following partially linear model:

$$
w_{i t}=\pi_{j} \text { cohort }_{j}+\phi_{t} d_{t}+m\left(\text { age }_{i t}\right)+\epsilon_{i t},
$$

where $w_{i t}$ is the mean or variance of the logarithm of consumption or income, evaluated for year $t(t=2000,2001, \ldots, 2010)$ and cohort group $i$ with age of household head age $e_{i t}$, while $\epsilon_{i t}$ is an independent, zero mean, random error. In this specification, I control for cohort, time and age effects using dummy variables cohort ${ }_{j}, d_{t}$ and a smooth function $m()$ which satisfies $m\left(a g e_{i t}\right)=$ $E\left(w_{i t} \mid a g e_{i t}\right){ }^{3} \quad$ While constructing cohort dummies, I cluster households using a five-year span. More precisely, having assigned to every cohort the date of birth of household head (in short DateOfBirth) from the set $I=\{1915,1916, \ldots, 1992\}$, the cohort dummies are defined as follows

cohort $_{1}=1$ if DateOfBirth $\in I_{1}=\{1988,1989,1990,1991,1992\}$ else cohort $_{1}=0$

cohort $_{2}=1$ if DateOfBirth $\in I_{2}=\{1983,1984,1985,1986,1987\}$ else cohort $_{2}=0$

\footnotetext{
${ }^{1}$ For the same reasons, while evaluating the profiles for educated households only, I restrict the sample to household heads between 24 and 75 .

${ }^{2}$ However, there is a high dispersion of the size of year-cohort units, ranging from around 10 to more than 1000 individual records.

${ }^{3}$ Dummies for the oldest cohort and for 2010 are excluded.
} 
cohort $_{j}=1$ if DateOfBirth $\in I_{j}=$

$\{1988-5(j-1), 1989-5(j-1), 1990-5(j-1), 1991-5(j-1), 1992-5(j-1)\}$ else cohort $_{j}=0$.

Further, assuming that index $i$ also indicates the date of birth of household head, it holds that $i \in I_{j}$. Reducing the number of estimated dummy-cohort parameters with five-year spans eliminates the identification problem ${ }^{4}$ and increases the number of degrees of freedom.

According to equation (1), the dependent variable is explained by two components. The first one is parametric (linear) and consists of the cohort and year dummies. The other part is a nonparametric relationship linking the dependent variable to household heads' age. The model is estimated using a two-step Speckman (1988) procedure, which is a combination of the ordinary least squares and a standard kernel smoothing estimator. ${ }^{5}$ A detailed description of this procedure and its application to a life cycle framework is provided i.a. in the technical appendix to Fernández-Villaverde and Krueger (2007).The bandwidth parameter $h$ is set to 2 and was chosen using a cross-validation method carried out on the average logarithm of consumption (the detailed results are available upon request).

Finally, to quantify the significance of the age-profiles' estimates, the $95 \%$ bootstrap confidence intervals (based on 500 replications) are calculated.. As discussed in the literature (see Hall, 1992; Neumann, 1995), in nonparametric regression the bootstrap method has an estimation bias. One way of dealing with this problem is to impose undersmoothing. Hence, while bootstrapping I set the bandwidth parameter $(h)$ to 1.8 .

\subsection{Average life cycle profile of income and consumption}

Figure 1 presents the average logarithm of households' available income ${ }^{6}$ with and without adjustment for the number of households members, while Table 1 summaries the changes in average received income. The average income profile exhibits a hump-shaped pattern known from the literature. Most notably, and consistently with Alessie et al. (1997), while a sharp increase is observed below the age of 30 , average income growth becomes moderate when household head is between 30 and 50. This pattern is even more evident when one controls for the household size.

One possible explanation for the rapid increase in the average income observed for households between 18 and 25 is a significant number of individuals who postpone their professional career in order to increase qualifications (or education). According to the 2009 HBS, 25\% of young household heads (aged from 18 to 25) declared that they were not looking for a job because they were still learning. However, excluding these households from the sample does not change the observed pattern significantly.

\footnotetext{
${ }^{4}$ Otherwise, the linear dependence of variables requires dropping one additional dummy and hence imposing additional assumptions. The common way of dealing with this problem is to attribute trend to cohort effects and apply a normalization which guarantees that time effects sum up to zero (see Deaton, 1997). However, this procedure fails if the number of years in the sample is small and/or if separating a trend from transitory shocks is difficult. In particular, distinguishing between trend and cycle is hard if one relies on data from a transition economy.

${ }^{5}$ The nonparametric component is estimated using a Nadaraya-Watson estimator with an Epanechnikov kernel.

${ }^{6}$ More precisely, Figure 1 depicts the estimates for households born between 1958 and 1962, calculated for 2007 (i.e. $\hat{\pi}_{7}+\hat{\phi}_{2007}+\hat{m}($ age $\left.)\right)$. This applies to all life cycle profiles presented in the article.
} 
To further analyze this issue, the life cycle income profile was estimated separately for households with and without an academic degree (see Figure 2). It turns out that a significantly higher growth rate in the 25-30 phase of life occurs only for the more educated individuals.

The life cycle consumption profile roughly mimics that of income (see Figure 3), but the former is significantly lower than the latter throughout the life cycle. This reflects accumulation of financial and/or capital (especially housing) wealth over the life cycle. The evident similarities in the shapes of both profiles might indicate that Polish households smooth their consumption over the life only to a very limited extent. ${ }^{7}$

The savings rate (defined as a difference between the logarithm of available income and consumption) is lowest for the youngest households, but starting at the age of 30 it remains quite stable or even slightly increases. In particular, the savings rate levels off or even grows after retirement. This pattern, called the retirement puzzle, has already been pointed out in the literature (see Banks et al., 1998; Blau, 2008), and, next to a bequest motive, it might also reflect the need to insure against sickness or some random events that are difficult to predict in a fast changing environment. Overall, the life cycle profile for consumption follows very closely that of income. This is also the case when high and low educated households are analyzed separately. In particular, average consumption tends to increase sharply for households aged between 18 and 30. This non-linear increase in consumption over the life cycle in Poland is different from the findings for developed economies. For example, Fernández-Villaverde and Krueger (2007) use the US data and estimate that the average consumption over the life cycle grows at a stable rate.

\subsection{Inequality in income and consumption over the life cycle}

The age-variance profile of income at the household level is depicted in Figure 4. In line with the previous literature, there is a significant rise in the inequality over the life cycle up to household head's age of 55. This profile is highly nonlinear. While a significant increase in income inequality is observed up to the age of 30, the age-variance profile flattens between 30 and 40 and then starts enhancing again. This last increase, however, can be attributed to changes in family composition and disappears if one controls for the household size (black line in Figure 4). Hence, the adult equivalent income inequality rises sharply in the early stage of the life cycle and remains at a fairly stable level afterwards.

How might this inequality profile be related to the individual income process? Following Storesletten et al. (2004), let us assume that for household $i$ with household head aged $h$ the idiosyncratic component of the logarithm of income can be expressed as

$$
\begin{gathered}
u_{i h}=\alpha_{i}+\epsilon_{i h}+z_{i h}, \\
z_{i h}=\rho z_{i, h-1}+\mu_{i h}, \\
\alpha_{i} \sim N\left(0, \sigma_{\alpha}^{2}\right), \quad \epsilon_{i h} \sim N\left(0, \sigma_{\epsilon}^{2}\right), \quad \mu_{i h} \sim N\left(0, \sigma_{\mu}^{2}\right), \quad \epsilon_{i h} \perp \alpha_{i} \perp \mu_{i h} \text { i.i.d., } \quad z_{i 0}=0, \quad E_{i}\left(u_{i h}\right)=0,
\end{gathered}
$$

where $\alpha_{i}$ is a fixed effect while $z_{i h}$ and $\epsilon_{i h}$ are persistent and transitory life-cycle shocks, respectively. Hence, the variance of the logarithm of income can be written as:

\footnotetext{
${ }^{7}$ Leszkiewicz-Kędzior and Welfe (2012) argue that only less than ten percent of all individuals consider their permanent income during the consumption decision-making process.
} 


$$
\operatorname{Var}_{i}\left(u_{i h}\right)=\sigma_{\alpha}^{2}+\sigma_{\epsilon}^{2}+\sigma_{\mu}^{2} \sum_{j=0}^{h-1} \rho^{2 j}
$$

As shown by Storesletten et al. (2004), income inequality in the US follows an approximately linear trend over the life cycle and therefore $\rho$ does not differ significantly from one. A different shape of the life cycle inequality is observed for Poland. The age-variance profile is hump-shaped, which in terms of the above model indicates that $\rho$ is below one. Assuming that all other parameters for these two countries are similar, this result suggests that the income process in Poland exhibits less persistence than that in the US. The estimates of income mobility presented in the next section confirm this finding.

Moreover, there exist heterogeneity in income inequality over the life cycle between households with and without an academic degree (see Figure 5). While the inequality pattern for all individuals is dominated by the shape of the less educated households, income inequality between households with a university degree exhibits a growing, roughly linear trend over the life cycle.

The confidence intervals associated with these inequality profiles are substantially wider than those for age-means. However, the shapes of individual bootstrap profiles are very similar. The only exception is the variance-profile for educated households, which is estimated with a relatively low precision.

As regards consumption inequality (see Figure 6), after a rise in the early phase of life, even a slight decrease is observed as from the age of 30.The latter is clearly in contrast to the earlier literature. However, taking into account wide confidence intervals, this result is not statictically significant.

\subsection{Robustness checks}

At this point I present some sensitivity analysis of the results presented above. First, the life cycle profile of the logarithm of consumption was calculated using two alternative equivalence scales: the OECD scale (weights: 1 for the household head, 0.7 for each subsequent adult, 0.5 for each child) and the OECD modified scale (weights: 1 for the household head, 0.5 for each subsequent adult, 0.3 for each child). Although there are some dissimilarities between the results (see Figure 7), the main qualitative findings remain unchanged.

Another robustness check concerned the bandwidth parameter in the Speckman (1988) procedure. Assuringly, the means of the logarithm of consumption over the life cycle estimated using alternative values of $h(h=1,3,5,7,10)$ were very similar (see Figure 8).

As regards households' income data, the HBS is undoubtedly the most accurate and reliable Polish database. Still, it is not the only one. The Social Diagnostics (SD) (see the next section and the Data appendix for more details), which is a publicly available academic project covering many aspects of households' life, also contains some information on households' income. Therefore, the mean and the variance of the logarithm of income over the life cycle were also calculated using this database. The results confirm the shapes of the life cycle patterns estimated with the HBS data (see Figures 4 and 9). Some quantitative differences are most probably driven by lower quality of the income data from the Social Diagnostics. 


\section{Relative income mobility in Poland in 1999-2008}

This section is focused on income mobility observed for Polish households over the period 1999-2008. First, a database and an estimation technique are described. Next, the estimates for transition matrices and corresponding summary statistics are discussed and compared with the results from similar studies devoted to other (both developed and developing) countries, with special attention given to the US. Finally, in order to eliminate the influence of different shapes of the income distribution on the income mobility estimates in Poland and the US, some alternative mobility indices are calculated and discussed.

\subsection{Data}

In this study, the estimates of relative income mobility are obtained for Poland over the period 1999-2008. Since panel data are essential to address this problem, the HBS is not a coherent database to rely on in this matter. Therefore, unlike the rest of the article, this part is based on the data from the SD. This panel study is designed to cover many aspects of households' life, mainly subjective quality of life and other social dimensions (see the Data appendix for a more detailed description of the SD dataset and its comparison with the HBS). It also contains information on available income and allows to track individual households over time. It is important to keep in mind that since the SD is focused mainly on the social rather than financial aspects of households' life, the income data available in the SD are substantially less precise than in the HBS. However, while assessing income mobility, the relative rather than absolute aspect of income is of the essence. Therefore, the SD seems to be sufficiently accurate for this kind of analysis.

\subsection{Estimation method}

I construct the income transition matrices relying on five consecutive waves of the SD (2000, 2003, 2005, 2007 and 2009). Most calculations are based on a sample of households with household head aged between 18 and 85. The average declared monthly total net income from the previous year was used to divide households into income quintiles. The matrices with and without a correction for a household size were constructed. In the former case, the OECD square root equivalence scale was applied, i.e. each household's income was divided by the square root of its size measured by the number of household members. Additionally, in order to control for the life cycle income profile discussed in the previous section, quintiles are also calculated on the basis of income adjusted for the age effect. ${ }^{8}$

The transition matrices are presented in the common form, where the first quintile represents the poorest group while row $i$ and column $j$ shows the fraction of households in income quintile $i$ in a given year that occupy income quintile $j$ in a subsequent year. In order to ensure that each row or column of these matrices adds up to unity, if households at the quintile cutoffs have the same income, they are allocated randomly to the adjacent quintiles. ${ }^{9}$

To obtain the final output, i.e. the average annual transition matrix for the period 1999-2008, I proceed as follows. First, I construct four mobility matrices $A_{y_{1}: y_{2}}$ for 2(3)-year periods, the

\footnotetext{
${ }^{8}$ Income adjusted for the age effect equals individual income divided by the average life cycle income estimated in the previous section.

${ }^{9}$ In order to check the sensitivity of the results to this randomization, I recalculated the matrices, this time assigning the households with an identical income to the same cluster. The results were broadly unchanged.
} 
multiplication of which gives me the nine-year transition matrix $\left(A_{2000: 2009}=A_{2000: 2003} * A_{2003: 2005} *\right.$ $\left.A_{2005: 2007} * A_{2007: 2009}\right) .{ }^{10}$ The final one-year period matrix $(B)$ satisfies the following equation: $B=A_{2000: 2009}^{1 / 9}=V D^{1 / 9} V^{-1}$, where $V D V^{-1}(D$ - diagonal $)$ is a spectral decomposition of matrix $A_{2000: 2009 \cdot{ }^{11}}$

Calculating the average transition matrix is appealing for at least two reasons. First, it allows to use all available information and maintain the statistical correctness of the results. Second, such a transformation is very convenient for comparative purposes.

On the basis of the obtained matrices, the following summary indicators of income mobility are calculated: (1) the average quintile move (see Khor and Pencavel, 2006 for the formula), (2) the immobility ratio, defined as the fraction of households that remain in the same quintile (3) the adjusted immobility ratio, defined as the fraction of those who remain in the same quintile or move to an adjacent quintile, (4) the distance between the calculated matrix and the perfect mobility benchmark proposed by Shorrocks (1978), i.e. one minus the second greatest eigenvalue of a matrix, and (5) the Sommers and Conlisk (1979) measure of mobility, calculated as one minus the product of all eigenvalues.

\subsection{Results}

The transition matrices and corresponding income mobility indices are presented in Tables 2 and 3. The chi-square test for the symmetry of the matrices (see Khor and Pencavel, 2010 for an exact formula) cannot be rejected at any conventional level of confidence. At least fifteen percent of households with household head aged between 18 and 85 who occupy the lowest quintile in one period leave that quintile next year (see the left matrix from the top panel of Table 2). On the other hand, less than eighty percent of Polish households remain in the top rank in two subsequent years. Hence, staying in the same quintile appears to be more persistent for the poorest households. This property, also observed in Russia (see Lukiyanova and Oshchepkov, 2011), is not characteristic for the US (see Table 4). Moreover, in the center of the income distribution there is even more mobility with probabilities of remaining in the same rank for the second, third and fourth quintiles lying between $60-70$ percent.

Since the main goal of this study is to analyze idiosyncratic aspects of income mobility, those individuals' movements in income distribution that are caused by choosing between education and work or resulting from retirement are not of a particular interest. However, restricting the sample to working-age households (a household head aged between 25 and 65) turns out to add to income mobility, decreasing the immobility ratio from 0.72 to 0.68 . This result is a consequence of excluding from the sample retired households whose income shows less variability. Nevertheless, the difference in income mobility between working-age households and the total sample is rather small. Further, adjusting for the households size increases slightly individuals' movements in income distribution, while imposing correction for the life cycle income profile leaves the estimates of income mobility broadly unchanged. Examining urban and rural households separately does

\footnotetext{
${ }^{10}$ These matrices are calculated based on the following pairs of the SD waves: 2000 and 2003, 2003 and 2005, 2005 and 2007, 2007 and 2009. For each of these pairs there is roughly 2000-3300 individual records. Obtaining the nine-year transition matrix $A_{2000: 2009}$ directly is inefficient as it would rely on less than 1000 records.

${ }^{11}$ Distinct eigenvalues are a sufficient condition for the existence of such a decomposition of a quadratic matrix. However, this method of calculating the m-period average annual transition matrix has its limitations. First, with "m" being an even number, there might be more than one solution. Second, the average transition matrix might not exist, i.e. $B$ can have negative entries if transition probabilities substantially vary over time.
} 
not show significant differences between these two groups, either. Generally, the results obtained for Poland are fairly robust to alternative specifications.

How income-mobile are Polish households in comparison to other countries? First, I focus on the difference vis-a-vis the developed economies. Since the existing cross-country analyses (Aaberge et al., 2002; Burkhauser et al., 1998) clearly show that the differences in income mobility between the US and old EU countries are usually found to be very small, and also income mobility in the US was a topic of a number of comprehensive empirical studies, I use this country as a benchmark. The estimates of income mobility in the US are taken from Díaz-Giménez et al. (2011) and annualized using the eigenvalue decomposition described in the previous subsection. ${ }^{12}$ Table 3 shows the summary results while the average annual transition matrix for the US is presented in Table 4.

Polish households appear to be more mobile in terms of income than the American ones according to all mobility indices. ${ }^{13}$ The smallest difference is observed for the adjusted immobility ratio, which suggests that the main difference between Polish and US households' mobility concerns movements between adjacent quintiles.

As regards the mobility indices for other countries, direct comparisons are difficult due to methodological differences (sample, equivalence scales, income measures etc.) and hence one needs to be cautious while interpreting the results. A summary of immobility measures for selected countries with a short description of the main assumptions imposed are presented in Table 5. The reported results might suggest that the degree of mobility in Poland is more similar to that observed in China and Russia, i.e. developing or transition economies, than to that obtained for developed countries.

\subsubsection{Dispersion of income distribution and income mobility}

One of the factors that can be responsible for the dissimilarities in income mobility between different countries is inequality in income distribution. Generally, the narrower the income distribution, the more probable the jump for an individual from one quintile to another.

The quintiles of income in Poland and the US are reported in Table 6. According to these statistics, the income distribution in the US seems to be more disperse than in Poland. In particular, in the US (based on data from 2007, taken from Díaz-Giménez et al., 2011), the third quintile of income distribution was roughly 2.9 times greater than the first one, while an analogous statistics for Poland (according to the Polish HBS from 2010) was only $2.14^{14}$.

I next try to assess, to what extent the dissimilarities in income mobility between Polish and American households are driven by the differences in the shapes of their income distributions. To this end, an artificial distribution of income for Polish households is generated, such that it mimics that observed in the US. More specifically, the first quintile is kept unchanged and the relation between the first and the rest of quintiles is taken from the US data, see Table 6. Then, the average probability of remaining in the same "simulated quintile" for two consecutive years is quantified and shown in Table 7, together with the estimates calculated on the basis of the observed quintiles for Poland and the US. Except for the lowest and highest quintiles, these artificially generated

\footnotetext{
${ }^{12}$ The results are very similar if one uses instead individual income tax returns as the data source (see Table 4 for annual transition matrices calculated on the basis of these two studies).

${ }^{13}$ To ensure comparability to the US, I use here the results for Poland obtained for the whole sample without adjusting for family size and age effect (bolded row in Table 3).

${ }^{14}$ Based on the Polish HBS from 2000-2010, the relation between income quintiles in Poland was quite stable over time. The same pattern is observed while comparing the means and medians between the quintiles.
} 
probabilities are higher than those reported for the original data. In addition, there is a slight improvement in income immobility ratio, but still its value is significantly lower than that in the United States. Hence, adjusting for the inequality in income distribution reduces only slightly the observed differences in income mobility between Poland and the US.

\section{Concluding remarks}

In this paper I investigated the life cycle income and consumption patterns in Poland, relying on the estimates of the income and consumption distributions as well as the transition matrices of relative income mobility.

The main findings are as follows. The average income over the life cycle follows an inverted Ushape. For the educated households, the most intense increase is observed in the early phase of life, up to the age of 30 . The average consumption over the life cycle mimics quite closely the average income.

In contrast to a roughly linear increasing trend of income inequality over the life cycle obtained for the US, the age-variance profile for Poland is humped-shaped. More precisely, the income inequality increases sharply at the early phase of life and then remains quite stable up to the retirement age. This finding might indicate less persistence in individual income process. Indeed, the estimates of transition matrices for Poland confirm that relative income mobility is higher than that observed in developed countries.

Interestingly, the age-variance profile for more educated households differs from that obtained for the whole population and is similar to that for all US households. Hence, the rapid increase in the share of individuals with an academic degree that was observed in Poland during the economic transition should result in a gradual convergence of income inequality profile to that obtained for developed economies.

A natural extension of this study would be to investigate how the patterns obtained for Poland can be generalized to other economies in transition, especially ex-communist Central and Eastern European countries. It would also be interesting to examine to what extent the differences between Poland and developed economies that I identified at the micro level translate into different properties of macroeconomic aggregates. In this respect, general equilibrium models with heterogeneous households could serve as a useful laboratory. I leave these questions for future research.

\section{References}

Aaberge, R., A. Buörklund, M. Jäntti, M. Palme, P. Pedersen, N. Smith, And T. Wennemo (2002): "Income Inequality and Income Mobility in the Scandinavian Countries Compared to the United States," Review of Income and Wealth, 48, 443-469.

Abe, N. And T. Yamada (2009): "Nonlinear Income Variance Profiles and Consumption Inequality over the Life Cycle," Journal of the Japanese and International Economies, 23, 344-366.

Alessie, R., A. Lusardi, And T. Aldershof (1997): "Income and Wealth over the Life Cycle: Evidence from Panel Data," Review of Income and Wealth, 43, 1-32.

Auten, G. E. And G. Gee (2007): "Income Mobility in the U.S. from 1996 to 2005," Report, Department of Treasury. 
Banks, J., R. Blundell, And S. Tanner (1998): "Is There a Retirement-Savings Puzzle?" American Economic Review, 88, 769-788.

Blau, D. (2008): "Retirement and Consumption in a Life Cycle Model," Journal of Labor Economics, 26, 35-71.

Burkhauser, R., D. Holtz-Eakin, And S. Rhody (1998): "Mobility and Inequality in the 1980s: A Cross-National Comparison of the United States and Germany," in The Distribution of Welfare and Household Production, ed. by K. Jenkins and V. Praag, Elsevier, 111-175.

Cagetti, M. (2003): "Wealth Accumulation over the Life Cycle and Precautionary Savings," Journal of Business and Economic Statistics, 21, 339-353.

Díaz-Giménez, J., A. Glover, And J.-V. Ríos-Rull (2011): "Facts on the Distributions of Earnings, Income, and Wealth in the United States: 2007 Update," Quarterly Review, 34, 2-31.

Deaton, A. (1985): "Panel Data from Time Series of Cross-Sections," Journal of Econometrics, $30,109-126$.

(1997): The Analysis of Household Surveys: A Microeconomic Approach to Development Policy, Johns Hopkins University Press.

Deaton, A. And C. Paxson (1994): "Intertemporal Choice and Inequality," Journal of Political Economy, 102, 437-67.

FABIG, H. (1998): "Income Mobility in International Comparison - An Empirical Analysis with Panel Data," Report, Goethe University Frankfurt.

Fernández-Villaverde, J. And D. Krueger (2007): "Consumption over the Life Cycle: Facts from Consumer Expenditure Survey Data," The Review of Economics and Statistics, 89, $552-565$.

Gourinchas, P. And J. Parker (2002): "Consumption Over the Life Cycle," Econometrica, $70,47-89$.

Hall, P. (1992): "Effect of Bias Estimation on Coverage Accuracy of Bootstrap Confidence Intervals for a Probability Density," The Annals of Statistics, 675-694.

Khor, N. And J. Pencavel (2006): "Income Mobility of Individuals in China and the United States," Economics of Transition, 14, 417-458.

(2010): "Evolution of Income Mobility in the People's Republic of China: 1991-2002," ADB Economics Working Paper Series.

LeszkiewiCz-KęDzior, K. And W. Welfe (2012): "Consumption Function for Poland. Is Life Cycle Hypothesis Legitimate?" Bank i Kredyt, 43, 5-20.

Lukiyanova, A. And A. Oshchepkov (2011): "Income mobility in Russia (2000-2005)," Economic Systems, 36, 46-64.

Neumann, M. (1995): "Automatic Bandwidth Choice and Confidence Intervals in Nonparametric Regression," The Annals of Statistics, 23, 1937-1959. 
OECD (1996): Employment Outlook, OECD.

Shorrocks, A. (1978): "The Measurement of Mobility," Econometrica: Journal of the Econometric Society, 1013-1024.

Sommers, P. And J. Conlisk (1979): "Eigenvalue Immobility Measures for Markov Chains," Journal of Mathematical Sociology, 6, 253-276.

Speckman, P. (1988): "Kernel Smoothing in Partial Linear Models," Journal of the Royal Statistical Society. Series B (Methodological), 413-436.

Storesletten, K., C. I. Telmer, and A. Yaron (2004): "Consumption and Risk Sharing Over the Life Cycle," Journal of Monetary Economics, 51, 609-633.

YAnG, F. (2009): "Consumption over the Life Cycle: How Different is Housing?" Review of Economic Dynamics, 12, 423-443. 


\section{$5 \quad$ Figures and tables}

Figure 1: Average income over the life cycle

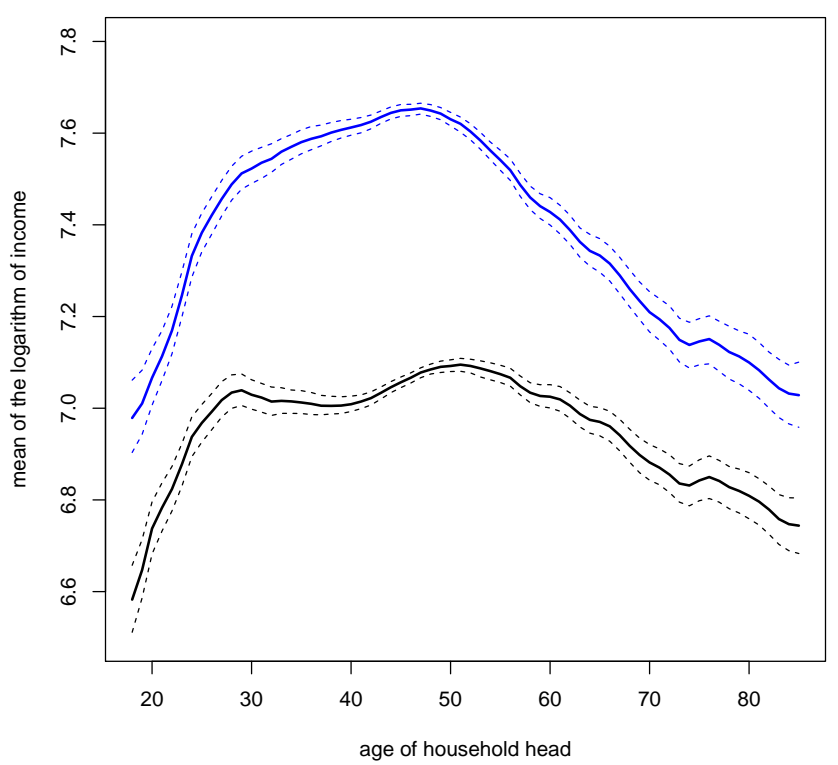

Notes: black line - square root equivalence scale; blue line - household level; dashed lines - 95\% bootstrap confidence intervals; estimates based on the Polish HBS 2000-2010.

Figure 2: Average income over the life cycle by educational groups

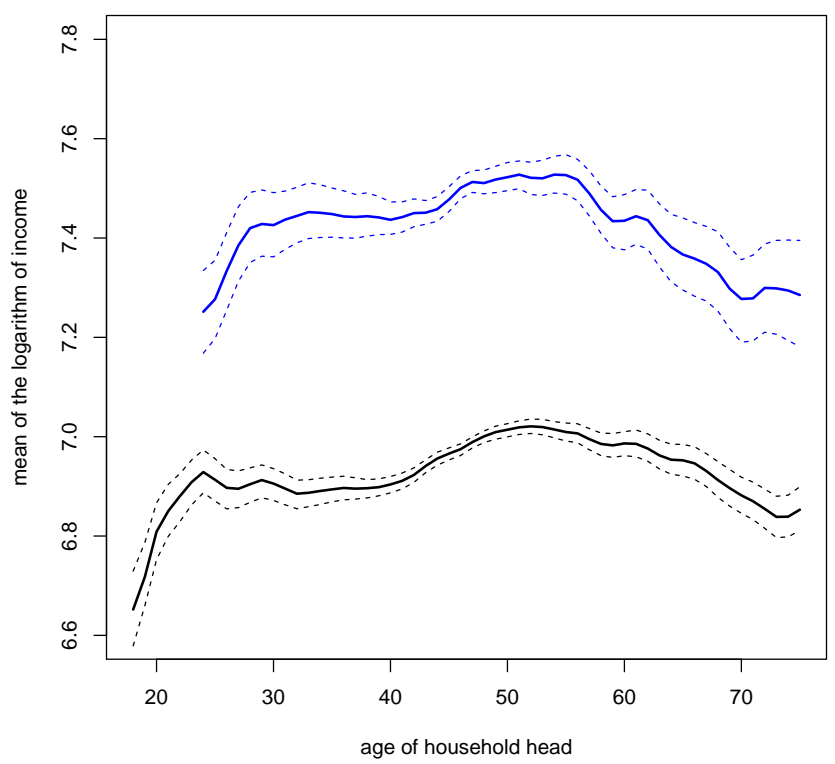

Notes: black line - without an academic degree; blue line - with an academic degree; dashed lines - 95\% bootstrap confidence intervals; estimates based on the Polish HBS 2000-2010, adult equivalent (square root equivalence scale). 
Figure 3: Average income and consumption over the life cycle

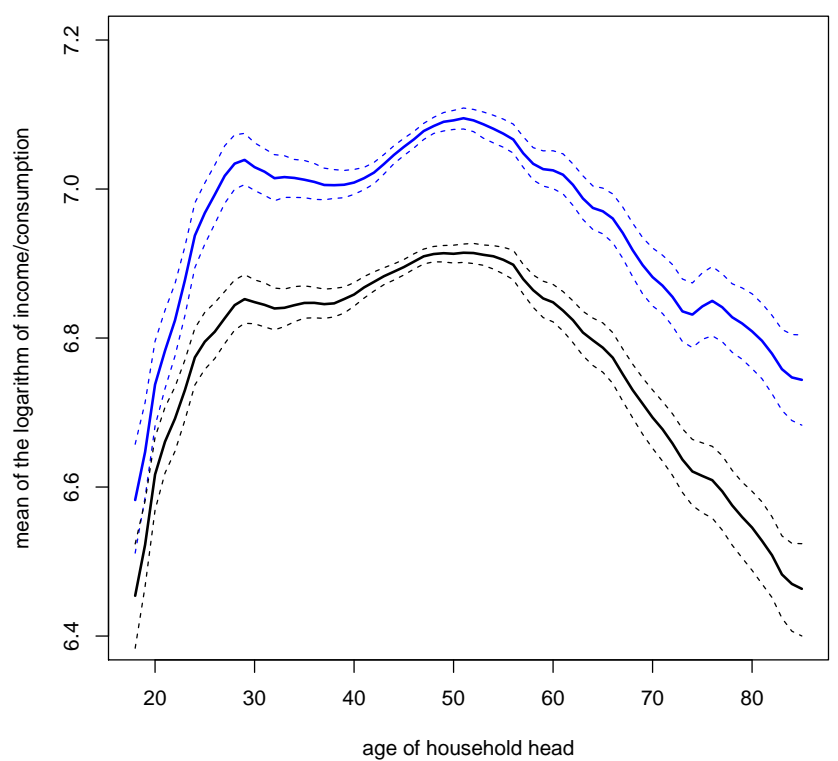

Notes: black line - consumption; blue line - income; dashed lines - $95 \%$ bootstrap confidence intervals; estimates based on the Polish HBS 2000-2010, adult equivalent (square root equivalence scale).

Figure 4: Inequality in income over the life cycle

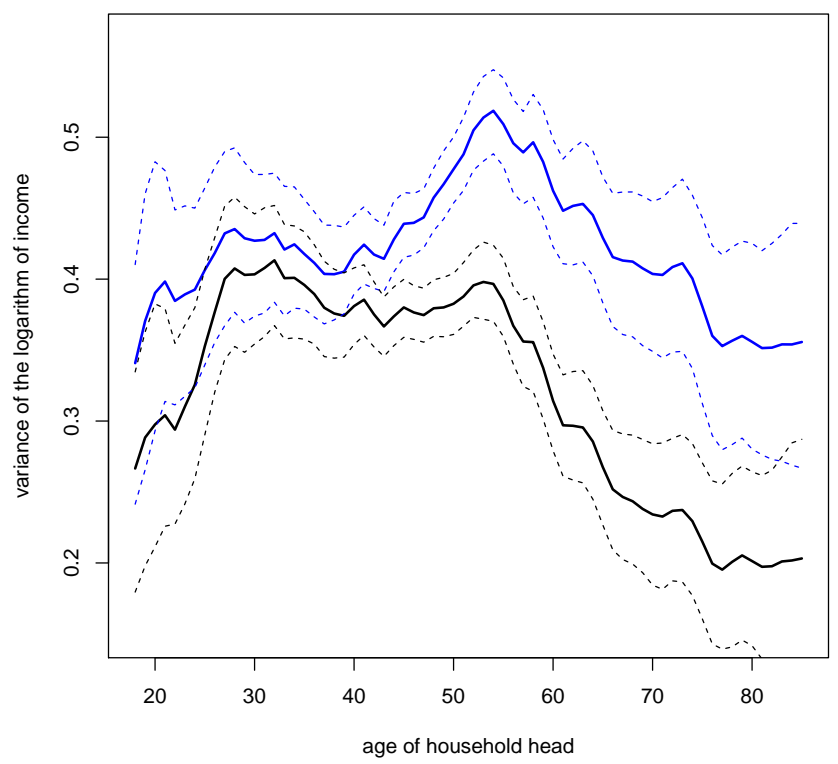

Notes: black line - square root equivalence scale; blue line - household level; dashed lines - 95\% bootstrap confidence intervals; estimates based on the Polish HBS 2000-2010. 
Figure 5: Inequality in income over the life cycle by educational groups

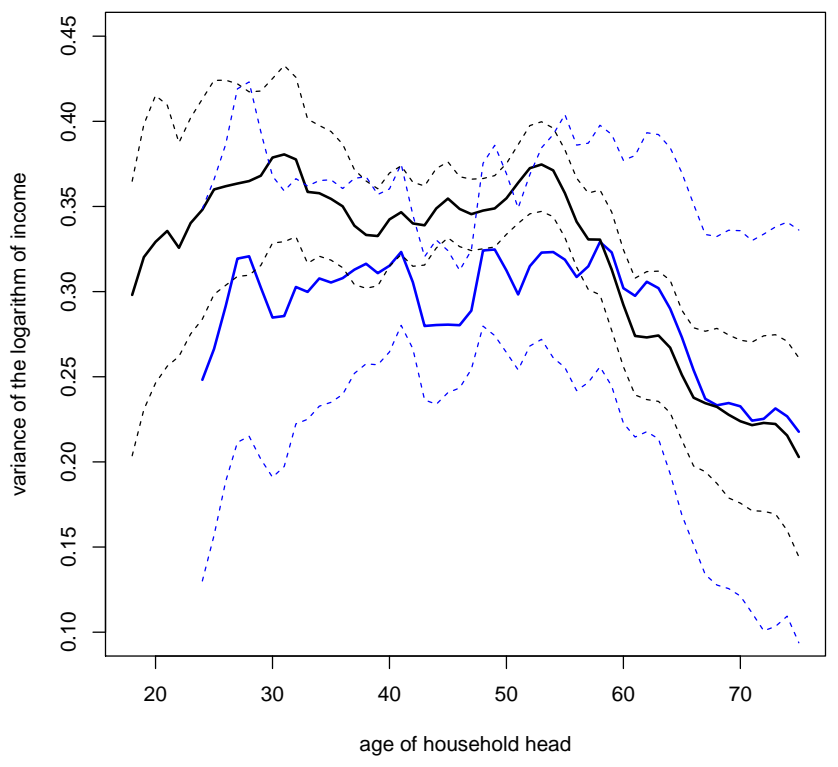

Notes: black line - without an academic degree; blue line - with an academic degree; dashed lines - 95\% bootstrap confidence intervals; estimates based on the Polish HBS 2000-2010, adult equivalent (square root equivalence scale).

Figure 6: Inequality in income and consumption over the life cycle

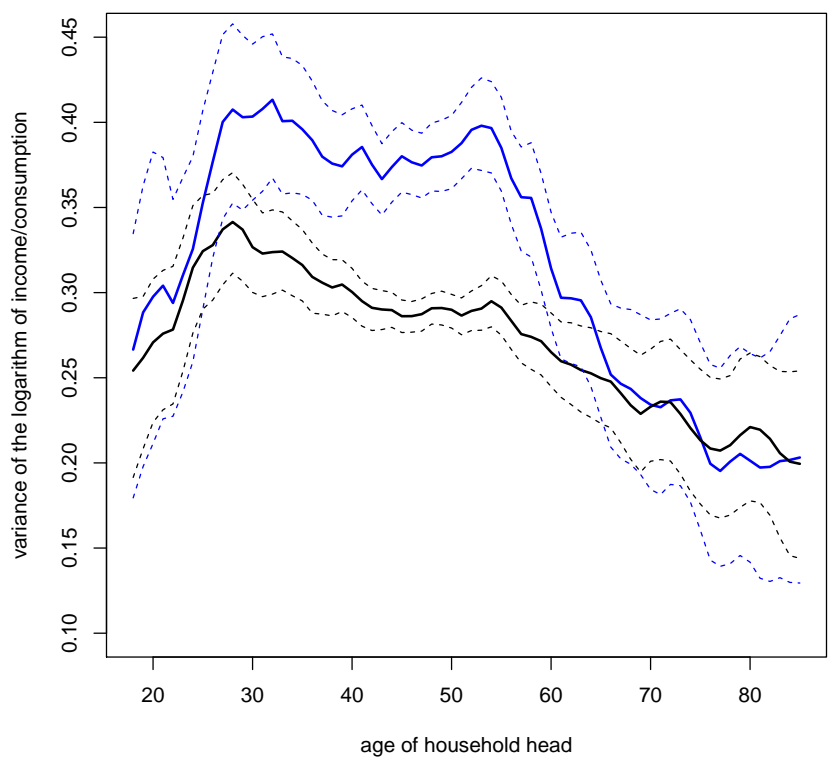

Notes: black line - income; blue line - consumption; dashed lines - 95\% bootstrap confidence intervals; estimates based on the Polish HBS 2000-2010, adult equivalent (square root equivalence scale). 
Figure 7: Average consumption over the life cycle and different equivalence scales

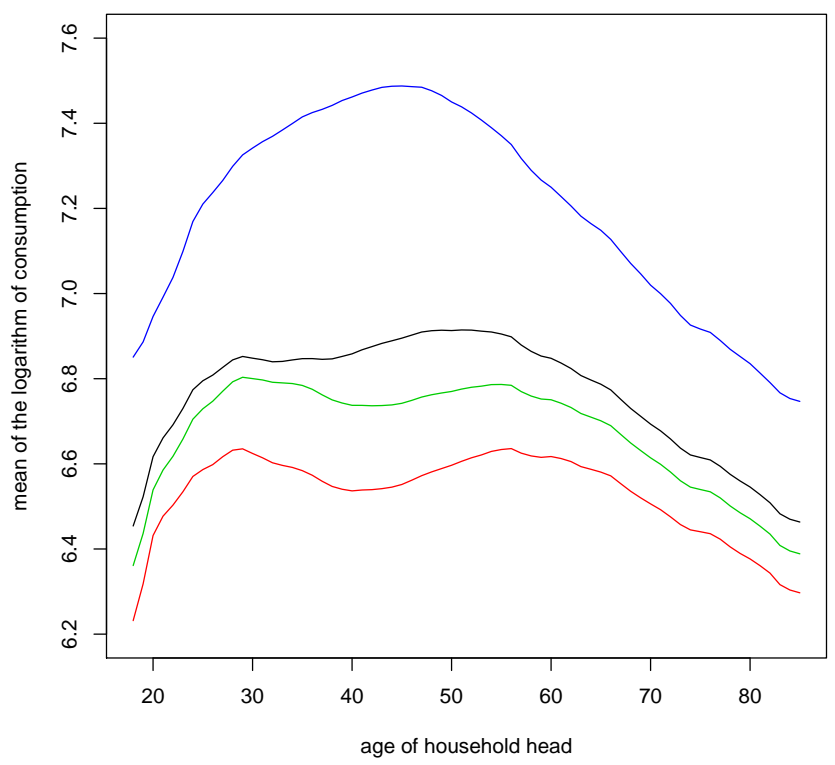

Notes: black line - square root scale ; blue line - household level; red line - OECD scale; green line - OECD modified scale; estimates based on the Polish HBS 2000-2010.

Figure 8: Average consumption over the life cycle and different bandwidth parameters

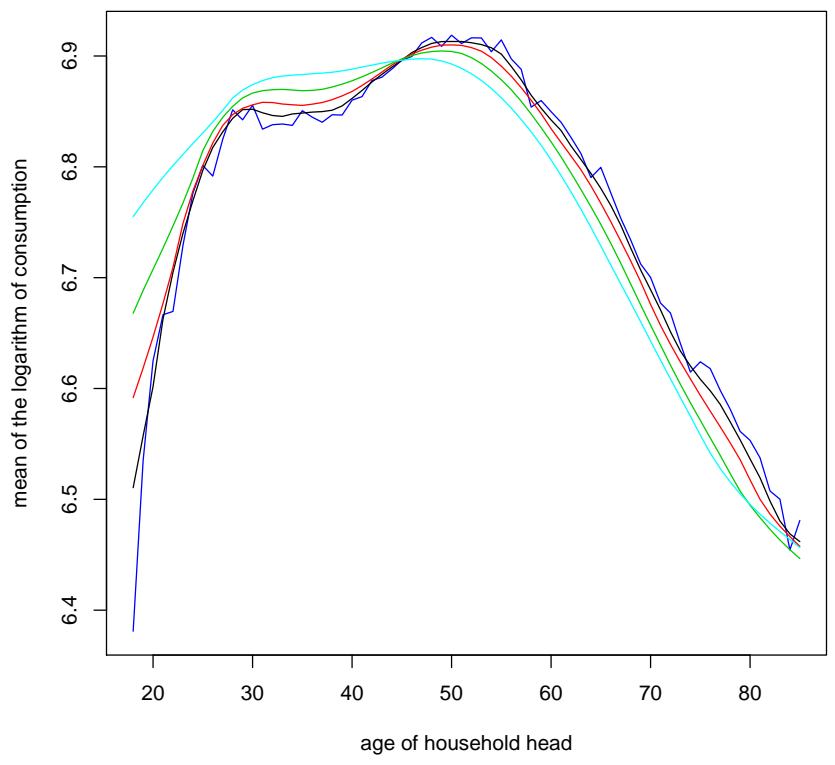

Notes: blue line $-\mathrm{h}=1$; black line $-\mathrm{h}=3$; red line $-\mathrm{h}=5$; green line $-\mathrm{h}=7$; azure line $-\mathrm{h}=10$; estimates based on the Polish HBS 2000-2010, adult equivalent (square root equivalence scale). 
Figure 9: Comparison of average income over the life cycle in the HBS and the SD

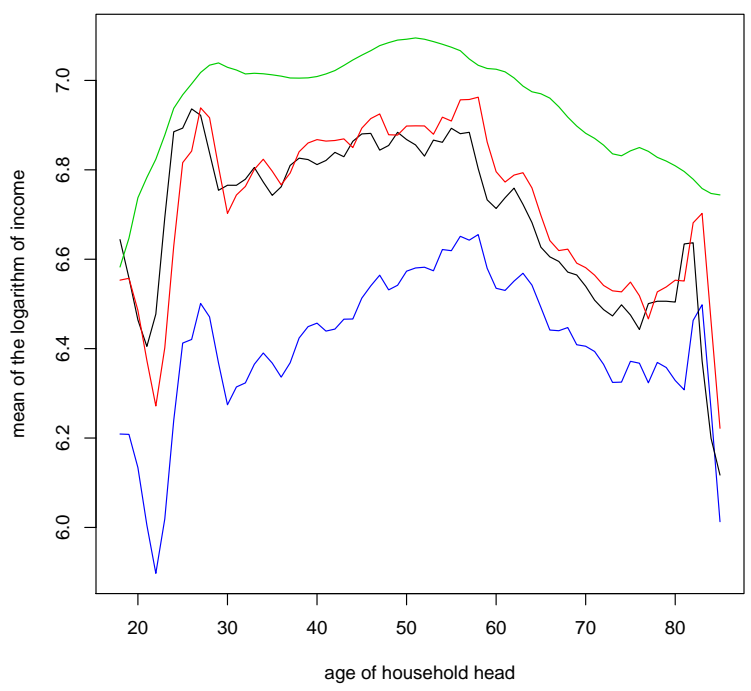

Figure 10: Comparison of inequality in income distribution over the life cycle in the HBS and the SD

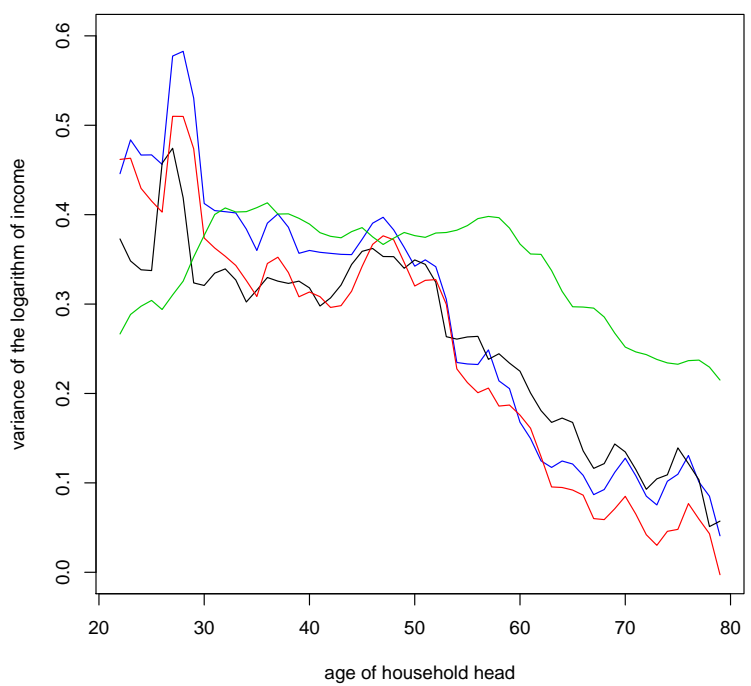

Notes:

black line -based on the SD (2000-2009), variable - average monthly total income from the previous year, square root eq. scale;

red line - based on the SD (2000-2009), variable - total income from the previous month, square root eq. scale;

blue line -based on the SD (2000-2009), variable - income from the previous month, equivalence scale proposed by the SD;

green line - based on the HBS 2000-2010. 
Table 1: Changes in household's average available income over the life cycle

\begin{tabular}{ccc}
\hline Household head aged between & Household level & Adult equivalent \\
\hline $25-20$ & $31.6 \%$ & $23.0 \%$ \\
$30-25$ & $14.0 \%$ & $6.2 \%$ \\
$35-30$ & $5.8 \%$ & $-1.7 \%$ \\
$40-35$ & $3.2 \%$ & $-0.4 \%$ \\
$45-40$ & $3.7 \%$ & $4.8 \%$ \\
$50-45$ & $-1.9 \%$ & $3.6 \%$ \\
$55-50$ & $-8.9 \%$ & $-1.8 \%$ \\
$60-55$ & $-11.3 \%$ & $-4.9 \%$ \\
$65-60$ & $-9.5 \%$ & $-5.5 \%$ \\
$70-65$ & $-12.4 \%$ & $-8.8 \%$ \\
$75-70$ & $-6.4 \%$ & $-3.9 \%$ \\
$80-75$ & $-4.6 \%$ & $-3.3 \%$ \\
$85-80$ & $-7.1 \%$ & $-6.5 \%$ \\
\hline
\end{tabular}

Table 2: Average annual income transition matrices, Polish households 1999-2008

\begin{tabular}{|c|c|c|c|c|c|c|c|c|c|c|c|}
\hline & \multicolumn{5}{|c|}{$\begin{array}{l}\text { Sample: household head aged between } 18 \text { and } 85 \\
\text { Eq. scale: NO, adjusted for age effect: NO }\end{array}$} & & \multicolumn{5}{|c|}{$\begin{array}{l}\text { Sample: household head aged between } 18 \text { and } 85 \\
\text { Eq. scale: YES, adjusted for age effect: NO }\end{array}$} \\
\hline & \multicolumn{5}{|c|}{ Income Quintiles } & & \multicolumn{5}{|c|}{ Income Quintiles } \\
\hline & Lowest & Second & Middle & Fourth & Highest & & Lowest & Second & Middle & Fourth & Highest \\
\hline Lowest & 0.84 & 0.11 & 0.03 & 0.02 & 0.01 & Lowest & 0.79 & 0.13 & 0.05 & 0.02 & 0.01 \\
\hline Second & 0.11 & 0.70 & 0.12 & 0.05 & 0.02 & Second & 0.14 & 0.63 & 0.15 & 0.06 & 0.03 \\
\hline Middle & 0.03 & 0.15 & 0.64 & 0.15 & 0.03 & Middle & 0.05 & 0.17 & 0.58 & 0.16 & 0.03 \\
\hline Fourth & 0.01 & 0.03 & 0.16 & 0.63 & 0.16 & Fourth & 0.01 & 0.05 & 0.18 & 0.62 & 0.14 \\
\hline \multirow[t]{5}{*}{ Highest } & 0.01 & 0.01 & 0.05 & 0.16 & 0.78 & Highest & 0.01 & 0.02 & 0.04 & 0.14 & 0.79 \\
\hline & \multirow{2}{*}{\multicolumn{5}{|c|}{$\begin{array}{l}\text { Sample: household head aged between } 25 \text { and } 65 \\
\text { Eq. scale: NO, adjusted for age effect: NO }\end{array}$}} & & \multirow{2}{*}{\multicolumn{5}{|c|}{$\begin{array}{l}\text { Sample: household head aged between } 18 \text { and } 85 \\
\text { Eq. scale: YES, adjusted for age effect: YES }\end{array}$}} \\
\hline & & & & & & & & & & & \\
\hline & \multicolumn{5}{|c|}{ Income Quintiles } & & \multicolumn{5}{|c|}{ Income Quintiles } \\
\hline & Lowest & Second & Middle & Fourth & Highest & & Lowest & Second & Middle & Fourth & Highest \\
\hline Lowest & 0.82 & 0.11 & 0.04 & 0.02 & 0.01 & Lowest & 0.80 & 0.13 & 0.04 & 0.02 & 0.01 \\
\hline Second & 0.12 & 0.67 & 0.14 & 0.06 & 0.01 & Second & 0.12 & 0.63 & 0.17 & 0.05 & 0.02 \\
\hline Middle & 0.04 & 0.15 & 0.59 & 0.18 & 0.04 & Middle & 0.05 & 0.18 & 0.58 & 0.16 & 0.04 \\
\hline Fourth & 0.01 & 0.06 & 0.19 & 0.56 & 0.19 & Fourth & 0.02 & 0.04 & 0.18 & 0.62 & 0.14 \\
\hline Highest & 0.01 & 0.01 & 0.03 & 0.19 & 0.76 & Highest & 0.01 & 0.02 & 0.04 & 0.14 & 0.79 \\
\hline
\end{tabular}


Table 3: Summary of income mobility, one-year horizon, indices for Poland and the US

\begin{tabular}{|c|c|c|c|c|c|c|c|c|c|c|}
\hline & & & & & 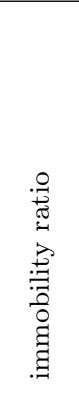 & 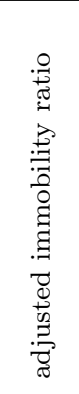 & 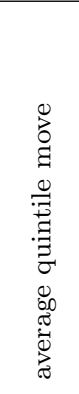 & 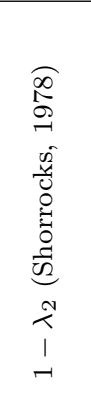 & $\begin{array}{c}\stackrel{\text { F }}{*} \\
* \\
\vdots \\
* \\
\text { F } \\
\dot{1}\end{array}$ & 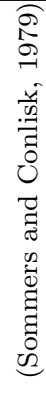 \\
\hline & eq. scale & age adj. & sample & urban/rural & & & & & & \\
\hline \multirow[t]{6}{*}{ POLAND } & NO & NO & age $18-85$ & both & 0.72 & 0.94 & 0.36 & 0.14 & 0.85 & \\
\hline & $\mathrm{NO}$ & NO & age $25-65$ & both & 0.68 & 0.93 & 0.41 & 0.16 & 0.90 & \\
\hline & YES & $\mathrm{NO}$ & age $18-85$ & both & 0.68 & 0.92 & 0.42 & 0.17 & 0.89 & \\
\hline & YES & YES & age $18-85$ & both & 0.68 & 0.93 & 0.41 & 0.16 & 0.89 & \\
\hline & $\mathrm{NO}$ & $\mathrm{NO}$ & age $18-85$ & urban & 0.72 & 0.94 & 0.36 & 0.13 & 0.85 & \\
\hline & $\mathrm{NO}$ & $\mathrm{NO}$ & age $18-85$ & rural & 0.70 & 0.93 & 0.40 & 0.15 & 0.85 & \\
\hline the US & $\mathrm{NO}$ & $\mathrm{NO}$ & & both & 0.87 & 0.98 & 0.15 & 0.05 & 0.53 & \\
\hline perfect mobility & & & & & 0.20 & 0.52 & 1.60 & 1.00 & 1.00 & \\
\hline complete immobility (identity matrix) & & & & & 1.00 & 1.00 & 0.00 & 0.00 & 0.00 & \\
\hline
\end{tabular}


Table 4: Annual income transition matrices for the US, based on the results from two different studies

\begin{tabular}{|c|c|c|c|c|c|}
\hline \multicolumn{6}{|c|}{$\begin{array}{l}\text { Calculated on the basis of } \\
\text { Díaz-Giménez et al. (2011) }\end{array}$} \\
\hline & \multicolumn{5}{|c|}{ Income Quintiles } \\
\hline & Lowest & Second & Middle & Fourth & Highest \\
\hline Lowest & 0.92 & 0.06 & 0.01 & 0.01 & 0.00 \\
\hline Second & 0.06 & 0.85 & 0.08 & 0.01 & 0.00 \\
\hline Middle & 0.01 & 0.08 & 0.82 & 0.08 & 0.01 \\
\hline Fourth & 0.01 & 0.01 & 0.10 & 0.83 & 0.06 \\
\hline Highest & 0.00 & 0.00 & 0.00 & 0.07 & 0.92 \\
\hline \multicolumn{6}{|c|}{$\begin{array}{l}\text { Calculated on the basis of } \\
\text { Auten and Gee (2007) } \\
\text { Data from } 1996 \text { and } 2005, \\
\text { based on individual income tax returns }\end{array}$} \\
\hline & \multicolumn{5}{|c|}{ Income Quintiles } \\
\hline & Lowest & Second & Middle & Fourth & Highest \\
\hline Lowest & 0.92 & 0.06 & 0.01 & 0.01 & 0.00 \\
\hline Second & 0.06 & 0.86 & 0.07 & 0.01 & 0.01 \\
\hline Middle & 0.01 & 0.08 & 0.84 & 0.07 & 0.01 \\
\hline Fourth & 0.01 & 0.01 & 0.08 & 0.86 & 0.05 \\
\hline Highest & 0.00 & 0.00 & 0.01 & 0.05 & 0.94 \\
\hline
\end{tabular}


Table 5: Income mobilty indices for selected countries

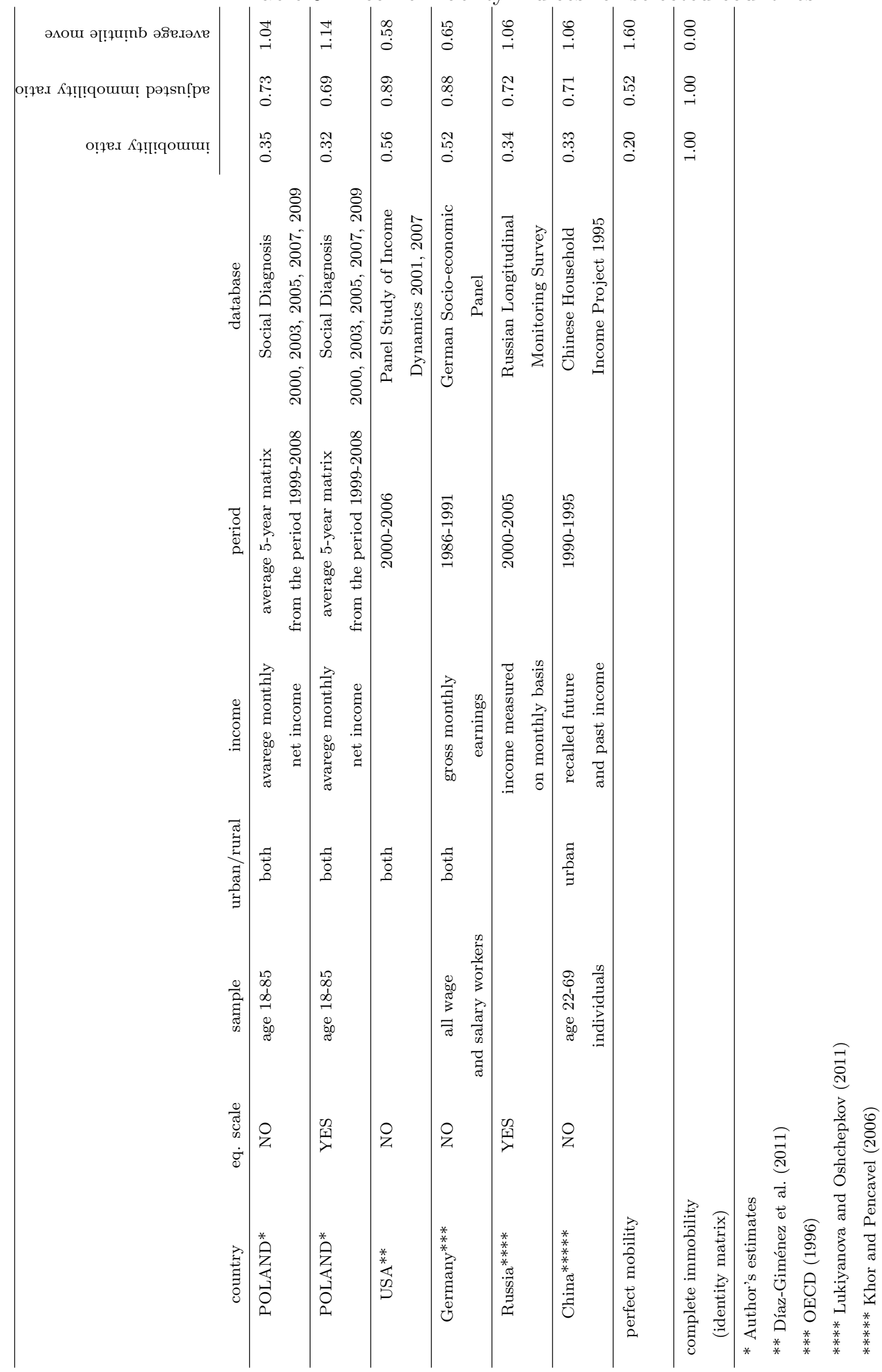


Table 6: Quintiles of income distribution in Poland and the US

\begin{tabular}{ccccc}
\hline & \multicolumn{4}{c}{ Quintiles $(\mathrm{Q} 20=100)$} \\
\cline { 2 - 5 } & 20 & 40 & 60 & 80 \\
\cline { 2 - 5 } Poland* & 100 & 155 & 214 & 303 \\
USA** & 100 & 181 & 293 & 491 \\
\hline
\end{tabular}

* From the Polish HBS, 2010.

** From Díaz-Giménez et al. (2011), data from 2007.

Table 7: Probability of remaining in the same quintile (2-year period) for Poland and the US, based on the observed and simulated quintiles

\begin{tabular}{rccccccc}
\hline & \multicolumn{8}{c}{ Based on the observed quintiles } \\
\cline { 2 - 8 } Poland & 0.72 & 0.52 & 0.45 & 0.45 & 0.63 & 0.55 \\
USA & 0.85 & 0.73 & 0.68 & 0.70 & 0.86 & 0.76 \\
\cline { 2 - 7 } & \multicolumn{6}{c}{ Based on the simulated quintiles } \\
\cline { 2 - 7 } Poland & Q1 & Q2 & Q3 & Q4 & Q5 & weighted immobility ratio* \\
\cline { 2 - 7 } share of population & 0.70 & 0.59 & 0.54 & 0.47 & 0.48 & 0.58 \\
\hline
\end{tabular}

* weighted with the share of population 
Table 8: Number of observations, top panel: in each cohort, based on the HBS 2009, low panel: for each 2(3)-year panels constructed using two adjacent waves, based on the SD 2000-2009.

\begin{tabular}{|c|c|c|c|c|c|c|c|}
\hline 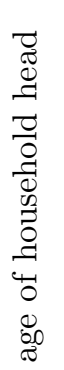 & 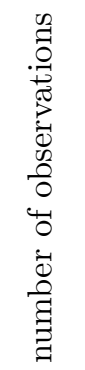 & 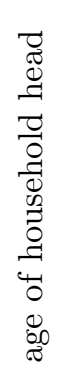 & 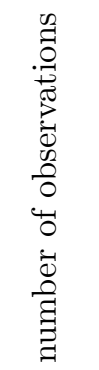 & 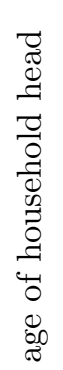 & 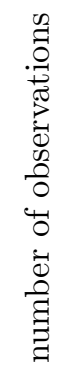 & 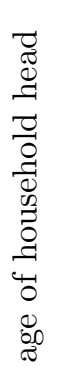 & 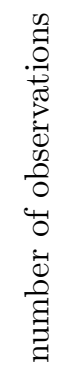 \\
\hline 18 & 10 & 38 & 678 & 58 & 865 & 78 & 348 \\
\hline 19 & 65 & 39 & 690 & 59 & 862 & 79 & 308 \\
\hline 20 & 118 & 40 & 656 & 60 & 846 & 80 & 239 \\
\hline 21 & 126 & 41 & 662 & 61 & 824 & 81 & 215 \\
\hline 22 & 187 & 42 & 679 & 62 & 740 & 82 & 195 \\
\hline 23 & 227 & 43 & 667 & 63 & 639 & 83 & 184 \\
\hline 24 & 248 & 44 & 773 & 64 & 441 & 84 & 143 \\
\hline 25 & 338 & 45 & 748 & 65 & 524 & 85 & 106 \\
\hline 26 & 333 & 46 & 739 & 66 & 459 & & \\
\hline 27 & 368 & 47 & 737 & 67 & 486 & & \\
\hline 28 & 433 & 48 & 815 & 68 & 467 & & \\
\hline 29 & 484 & 49 & 887 & 69 & 485 & & \\
\hline 30 & 508 & 50 & 950 & 70 & 495 & & \\
\hline 31 & 510 & 51 & 974 & 71 & 511 & & \\
\hline 32 & 577 & 52 & 966 & 72 & 437 & & \\
\hline 33 & 613 & 53 & 998 & 73 & 451 & & \\
\hline 34 & 634 & 54 & 981 & 74 & 409 & & \\
\hline 35 & 642 & 55 & 1014 & 75 & 386 & & \\
\hline 36 & 629 & 56 & 977 & 76 & 363 & & \\
\hline 37 & 608 & 57 & 953 & 77 & 341 & & \\
\hline
\end{tabular}

\begin{tabular}{cc}
\hline Panel & Number of observations \\
\hline $2000-2003$ & 2095 \\
$2003-2005$ & 2725 \\
$2005-2007$ & 2391 \\
$2007-2009$ & 3225 \\
\hline
\end{tabular}


Table 9: Selected demographic facts from the HBS and the SD

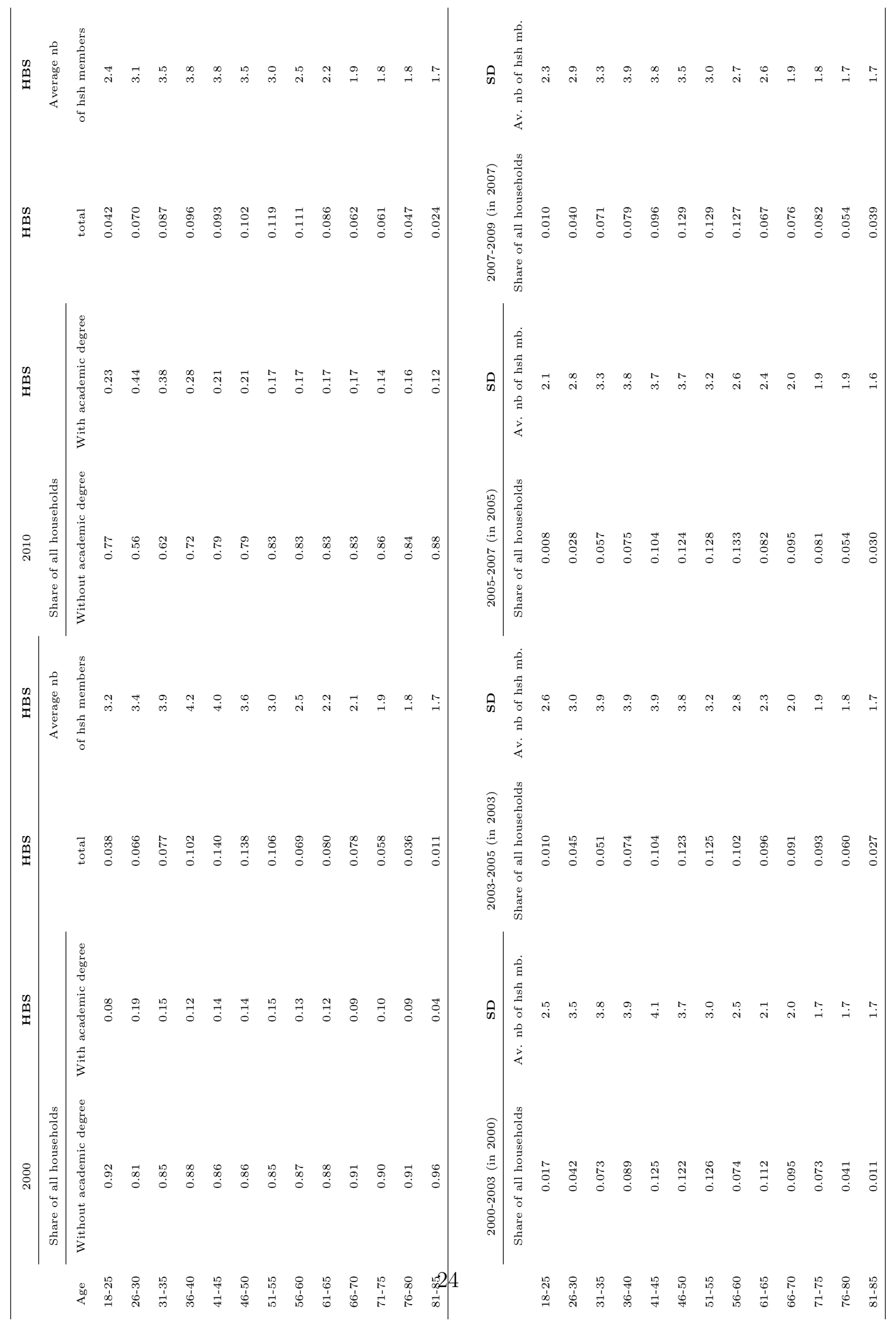


Table 10: Income concentration

\begin{tabular}{|c|c|c|c|c|c|c|}
\hline \multirow{2}{*}{\multicolumn{2}{|c|}{ Household Budget Survey, 2010}} & \multicolumn{5}{|c|}{ Quintiles } \\
\hline & & Lowest & Second & Middle & Fourth & Highest \\
\hline available income & & 0.066 & 0.116 & 0.167 & 0.230 & 0.421 \\
\hline disposable income & & 0.066 & 0.116 & 0.166 & 0.230 & 0.422 \\
\hline \multicolumn{7}{|c|}{ Social Diagnostics (from all 2(3)-year panels) } \\
\hline avalilable income & $\min$ & 0.053 & 0.112 & 0.165 & 0.228 & 0.387 \\
\hline \multirow[t]{2}{*}{ from previous year } & $\max$ & 0.078 & 0.125 & 0.174 & 0.238 & 0.429 \\
\hline & mean & 0.070 & 0.120 & 0.170 & 0.232 & 0.408 \\
\hline \multicolumn{7}{|c|}{ Social Diagnostics (year 2009 from 2007-2009 panel) } \\
\hline avalilable income from previous year & & 0.061 & 0.112 & 0.167 & 0.231 & 0.429 \\
\hline avalilable income from previous month & & 0.063 & 0.111 & 0.163 & 0.230 & 0.433 \\
\hline
\end{tabular}




\section{Data appendix}

Here I present the data from two major sources used in this paper. The first one is the HBS. Every year the Polish Central Statistical Office (CSO) publishes a report "Household Budget Surveys", which contains the main descriptive statistics and indicators calculated on the basis of the HBS, with methodological notes explaining i.a. how the survey is conducted. This report is publicly available on the CSO official website. Therefore, in this appendix I discuss only those HBS statistics which are crucial to the life cycle analysis. The second database is the Social Diagnostics, which is publicly available and can be downloaded from the website (see www.diagnoza.com). Since the data from this source were used in this study only to a limited extent, I also limit their discussion to the most important characteristics.

The HBS is conducted every year on a sample of around 37 thousand of Polish households. It collects households' monthly income and spending data, as well as a number of other socio-economic characteristics. In the HBS, several measures of income are reported. The major income statistics is the available income, which comprises total monthly net income form hired work, private farm or agriculture, other self-employment and free profession, from property, rental of a property or land, social insurance benefits, other social benefits and other income (including gifts and alimonies). The other income measure, disposable income, is defined as available income less expenditures on nonconsumption goods and services (for example expenditures on gifts donated to other households or some taxes). In order to ensure comparability between the HBS and the SD, I use available income, but this measure does not differ significantly from disposable income. To construct consumption profiles, total monthly expenditures on consumer goods and services are used. This measure of consumption includes neither changes nor flows from capital (especially housing) wealth.

In order to eliminate the seasonality in the data, it would be optimal to have income and consumption reported on annual basis. However, only monthly data are available and therefore those are used in this study. Monthly frequency of data should not affect the estimated means of income and consumption distributions, but one should keep in mind that the estimates of the variances are most probably overestimated.

Roughly 37 thousand of observations from the HBS spread unevenly over the households with different age of household head, in line with the structure of the population. Therefore, cohorts used to calculate the mean and the variance of income / consumption distribution vary considerably in size. The top panel of Table 8 presents the number of observations in such cohorts for year 2009. For each age of household head, there are between 10 and more than 1000 observations, with the average number of 544 .

The second part of this study relies on all adjacent waves from the SD 2000-2009. Therefore, the size of the panels used to construct the transition matrices varies between 2000 and 3300 observations (for exact numbers, see low panel of Table 8). In the SD, two major measures of income are reported: average monthly income from the previous year and monthly income from the last month. To avoid seasonality issues, I use the former.

The life cycle characteristics of the data such as the distribution of population according the age of household head and the average number of households slightly differ between the two datasets (see Table 9). For instance, young households are underrepresented in the SD, while the share of elderly individuals is greater than in the HBS.

Finally, these two databases are compared in terms of income concentration. Based on the HBS from 2000-2010, the shares of total households' income in each quintile of population (where households in a sample are ranked according to their available income) remained quite stable over time. 
20 percent of the richest generate more than 40 percent of total households' income, while the poorest 20 percent have at their disposal only less than 7 percent of income (see Table 10). This result remains unchanged when disposable rather than available income is used. Less precise estimates are obtained from different panels from the SD, probably due to the smaller number of observations and relatively lower quality of data. Nevertheless, no clear discrepancy in terms of income concentration is observed between the HBS and the SD. 


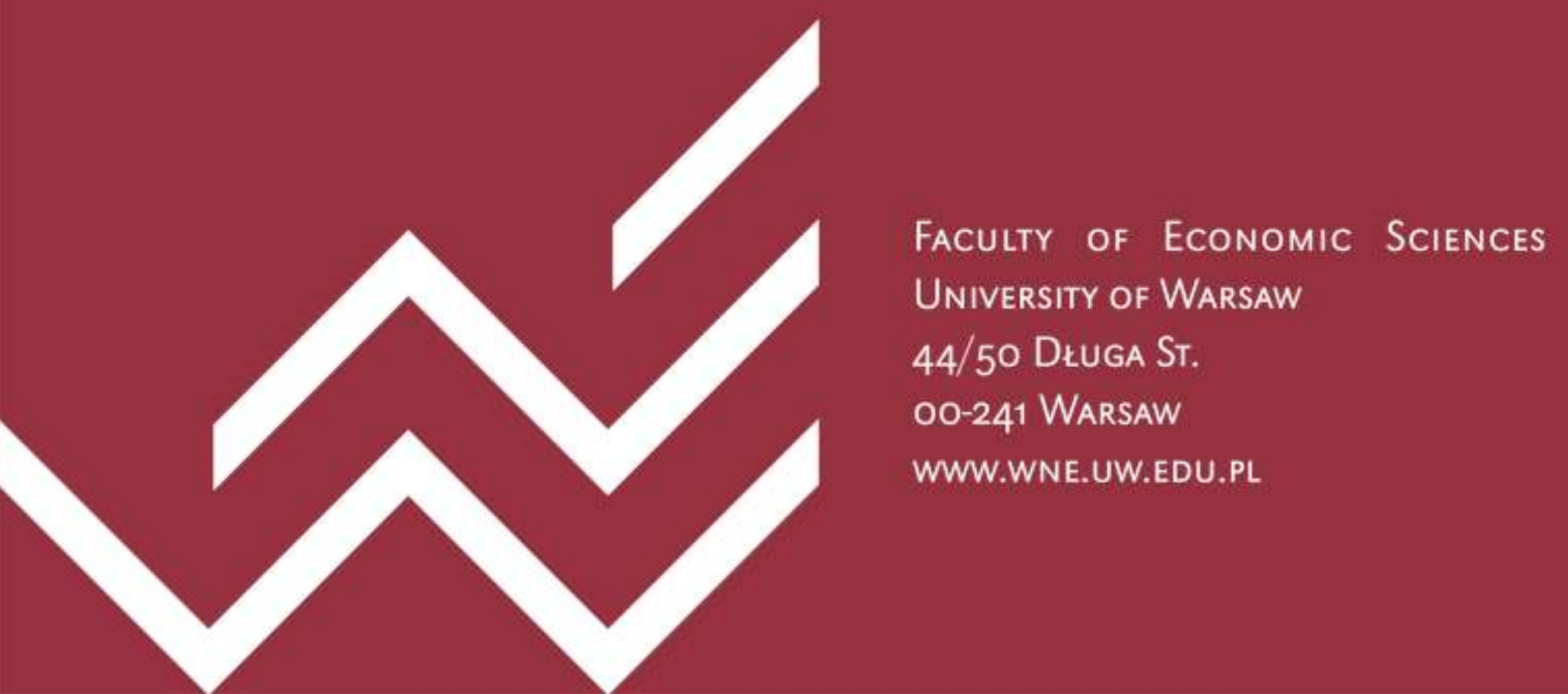

